\title{
Research on the Development of Dalian Ship and Ocean Engineering Industry
}

\author{
Shisong Zhang ${ }^{1, a^{*}}$, Yuanling Luan ${ }^{2, b}$ and Jianfei Zhang ${ }^{3, c}$ \\ 1, 2, 3 Dalian measurement and Control Technology Research Institute, NO. 16, BinhaiStreet, Zhongshan District, Dalian, \\ Liaoning, 116013, P. R. China \\ a394403007@qq.com, ${ }^{b} 435523253 @ q q . c o m,{ }^{c} 327570350 @ q q . c o m$ \\ *Shisong Zhang
}

\begin{abstract}
.
\section{Introduction}

Ship and marine engineering equipment industry is a modern comprehensive industry which provides technical equipment for water transportation, marine resources development and national defense construction. It is a strategic industry combining military and civilian, an important part of advanced equipment manufacturing industry, and plays an important basic role in the development of marine economy in our city. The development of marine and marine engineering equipment industry plays a very important role in improving Dalian's comprehensive strength of marine economy, upgrading the industrial structure of marine engineering equipment manufacturing, stepping into high-quality development and building a modern economic system.
\end{abstract}

The purpose of this paper is to determine the advantages and disadvantages of Dalian in shipbuilding, marine engineering equipment and other aspects through the analysis of the current situation of the development of Dalian's shipbuilding and marine engineering industry, and to put forward the strategic positioning, objectives and layout planning of the development. For the current shipbuilding industry in the environment of domestic low-end overcapacity and increasingly fierce international competition, how to adjust and optimize the upgrading of the industrial structure according to the changing trend of the market provides the relevant basis. Keywords: Dalian, ship and ocean engineering industry, SWOT analysis, development

\section{SWOT Analysis of Ship and Marine Engineering Industry}

\subsection{Strengths}

\subsubsection{Natural resources}

Dalian has a large number of islands, vast sea area, abundant tidal energy along the coast, vast beaches, abundant marine biological resources, marine science and technology has a certain accumulation and great potential for development.

\subsubsection{Transportation Location}

Dalian City is located on the eastern coast of Eurasia, the southernmost tip of Liaodong Peninsula in Northeast China, between 120 degrees 58 to 123 degrees 31 in the East and 38 degrees 43 to 40 degrees 10 in the north. It is bordered by the Yellow Sea in the east, Bohai Sea in the west, sea-separated from Shandong Peninsula in the South and vast Northeast Plain in the north. Liaoning Province is an important coastal port city in China, and the second largest city in the province. It is the main external gateway of Northeast China. It is also an important international shipping center, international logistics center and regional financial center in Northeast Asia. Dalian Port is the largest grain and oil transshipment port in China. It undertakes more than $70 \%$ of marine import and export goods and $90 \%$ of foreign trade container transportation in Northeast China. It has obvious location advantages.

\subsubsection{Industrial Foundation}

In recent years, large-scale shipbuilding enterprises such as Dalian Shipbuilding Heavy Industry, COSCO Shipping, COSCO Kawasaki Shipping and so on, have been able to independently complete various types of shipbuilding from fishing vessels to aircraft carriers. Dalian has become an important national shipbuilding base. Marine economic development has complete elements. The advantages of marine resources are obvious, and the talents, funds, technology and infrastructure supporting the development of marine economy are constantly strengthened. Famous maritime universities, ocean universities, Naval Academies and ocean research institutes at home and abroad gather in Dalian, with a large number of professionals and strong 
R\&D strength. During the Twelfth Five-Year Plan period, investment in marine development increased through various channels, modern ports supporting the development of marine economy and the collection and distribution network composed of railways, highways and grade highways basically formed, and the sustainable development ability of marine economy increased significantly.

\subsection{Weaknesses}

First, from the current state of development and the overall competitiveness of the industry, Chinese marine industry is not enough to compete with South Korea, Singapore and European and American design enterprises in terms of technology, matching, talent, total contracting capacity and industrial chain development. It is a long way to go to expand and strengthen the marine industry.

Second, inadequate investment in marine science and technology. Although Dalian has developed marine science and technology support in China, and marine equipment manufacturing industry is an important strategic emerging industry, which integrates high-tech, high added value and talents, its design ability in the field of marine equipment manufacturing is insufficient, and it lacks the support of marine science and technology personnel and the mastery of core technology.

Third, the industrial structure needs to be optimized. In addition to the shipbuilding industry, Dalian is not well known in other areas of marine equipment manufacturing. Therefore, the development of high-end equipment manufacturing industry is the main direction of transformation and upgrading of Dalian's shipbuilding industry.

\subsection{Opportunities}

Although the shipbuilding industry is still in a difficult period, its fundamentals are gradually improving. At present, there are three main advantages:

First, shipping is still the main mode of transportation in international trade. With the global economic recovery, the demand for shipping volume will increase steadily. In the medium and long term, the shipping industry still has a large market space.

Second, the international marine environmental protection rules are becoming more and more stringent, which brings new demands for marine energy-saving and environmental protection equipment, as well as certain renewal needs for the whole ship.

Thirdly, Chinese policy support for the ship and marine engineering industry is still strong. On November 27, 2017, the Ministry of Industry and Information Technology and other eight departments jointly issued the Action Plan for the Sustainable and Healthy Development of Marine Engineering Equipment Manufacturing Industry (2017-2020). It puts forward a clear plan of action for the development of Chinese marine engineering equipment industry in the next three years. The development goals are as follows: by 2020, the international competitiveness and sustainable development ability of Chinese marine engineering equipment manufacturing industry will be significantly improved, and the industrial system will be improved. With further improvement, the degree of specialization, serialization, informationization and intellectualization has been continuously strengthened, and the product structure has moved towards the middle and high end, striving to enter the ranks of advanced countries in marine engineering equipment assembly and manufacturing. Made-in-China 2025 clearly states that the development of marine engineering equipment and high-tech shipbuilding should be emphasized. Dalian's shipbuilding industry has a deep manufacturing foundation. It owns large enterprises such as Dalian Shipbuilding Heavy Industry Group Co., Ltd. and Dalian Zhongyuan Shipping Engineering Co., Ltd. and so on. The industry development environment is superior. With the continuous introduction of these policies, the development of Dalian's shipbuilding and marine engineering industry will surely usher in new opportunities. From the perspective of internal factors, the release of reform dividends such as supply-side reform of shipbuilding industry and mixed ownership reform of central enterprises will effectively improve the quality of development of shipbuilding industry and fully stimulate the endogenous power of enterprises themselves.

\subsection{Threats}

Nowadays, the world shipbuilding industry market is not optimistic and facing the predicament of excess industry. At the same time, in the domestic shipbuilding industry, Shanghai Waigaoqiao Co., Ltd., Jiangsu Yangzijiang Shipping Industry (Holding) Co., Ltd., Jiangsu New Age Shipbuilding Co., Ltd. and Qingdao Beihai Ship Heavy Work Place rank the top four in the country for new ship orders, together with the continuous decline of orders in the world shipbuilding market. The traditional advantages of Dalian's shipbuilding industry are gradually weakening. Qingdao and Shanghai have developed marine science and technology resources, numerous research institutes involved in marine science and technology, leading the country in investment in marine science and technology. Qingdao has formed three major marine industry bases: high-tech zone, west coast zone and blue Silicon Valley core zone, which provide guarantee for the development of new marine industry in Qingdao.

The constraints of marine ecological environment are increasing day by day. Marine ecological environment is the natural basis of marine economic development. Compared with Shanghai, Shenzhen, Ningbo and other port cities, Dalian has insufficient investment in port infrastructure and marine pollution control. The contradiction between marine industry development and marine environmental pollution has become increasingly prominent, and marine environmental governance needs to be strengthened urgently. The ecological disasters caused by environmental 
pollution every year will directly affect the sustainable development of marine economy in Dalian.

\section{STRATEGIC POSITIONING, OBJECTIVES AND SPATIALLAYOUTPLANNINGFORTHEDEVELOPMENT OF SHIP AND MARINE ENGINEERING INDUSTRY}

\subsection{Strategic positioning}

Give full play to Dalian's geographic advantages and radiation functions, strengthen cross-regional industrial cooperation, do a good job in regional technical cooperation, strengthen independent research and development, independently design core accessories, build a development base for high-end marine equipment manufacturing industry, and strengthen the comprehensive competitiveness of shipbuilding industry. At the same time, attention should be paid to the combination with energy industry and military affairs, so as to form a rational industrial layout with clear functions and to develop in harmony with other industries in Dalian.

\subsection{Development Goals and Layout Planning of Ship and Marine Engineering Industry}

1) We will accelerate the transformation and upgrading of the shipbuilding industry and achieve innovative and green development. We will encourage shipbuilding enterprises to unite and restructure, promote modern shipbuilding models, focus on supporting the manufacture of high-tech ships and key supporting equipment, and cultivate a number of enterprises with strong international competitiveness.

2) Strengthen ship assembly capacity. With Dalian Shipbuilding Heavy Industry and Dalian COSCO Shipping as the core, we should strengthen the integration ability of the industry chain, and strengthen the shipbuilding industry system, which integrates shipbuilding, repairing, matching, technological research and development and testing facilities. The structure of the shipbuilding industry is more reasonable, the categories are increasingly complete and the complementarity is gradually enhanced. To resolve the overcapacity of shipbuilding, promote the development of military-civilian integration, encourage military enterprises to produce civil infrastructure and "civilian participation in the army"; support the construction of enterprise informatization, and build intelligent shipyards. We will promote the localization and scale of core technologies and key components to enhance the competitiveness of the shipbuilding industry.

3) We will further improve the ship's comprehensive supporting system. Focusing on the research and development of new marine auxiliary products such as Dalian marine diesel engine, Dalian marine propeller and Dalian marine valve, we should strengthen the technology import, digestion and absorption of key marine auxiliary products, tackle key technical problems and product development, and strengthen the capacity of independent construction of auxiliary equipment.

4) Further optimize the spatial layout of shipbuilding industry. We will promote the cluster development of shipbuilding industries in Dalian Bay, Changxing Island and Lushun. Dalian Bay Base will focus on the development of large-scale ship manufacturing, marine engineering equipment manufacturing, ship supporting equipment manufacturing, ship key components and other industries; Changxing Island Base will accelerate the introduction of internationally competitive ship and marine engineering equipment enterprises, focusing on the development of ship manufacturing, marine engineering equipment manufacturing, ship supporting equipment manufacturing and other industries; Lushun Base will focus on the development of large-scale ships; Shipbuilding, special ship manufacturing, ship repair and other industries. 5) We will consolidate and expand the manufacturing industry of marine engineering equipment. Efforts should be made to improve the ability of independent $R \& D$ and break through the bottleneck of key technologies. With Dalian Shipbuilding Heavy Industry and Dalian COSCO Shipping as the main backbone enterprises, we will focus on the development of offshore oil and gas development engineering equipment with large offshore structures or super large offshore floating platforms as the core, and expand the manufacture of marine engineering equipment such as seawater utilization, marine environmental protection special instruments and marine electric power. Focus on promoting the gathering and development of marine engineering equipment manufacturing industry, such as Dalian Bay Coastal Equipment Manufacturing Agglomeration Zone, Dalian Sanlibao Coastal Industrial Zone and Lushun Economic and Technological Development Zone, to build a comprehensive marine equipment manufacturing base with international competitiveness.

\section{DEVELOPMENTGOALSANDLAYOUTPLANNINGOF OTHER RELATED INDUSTRIES}

1) Develop high-tech Shipbreaking industry and develop green and environmentally friendly Shipbreaking technology. Traditional Shipbreaking industry is a highly polluted industry, which has many problems, such as residual oil pollution discharge, waste metal and waste disposal. Dalian should seize the opportunity of overcapacity after the international financial crisis and the improvement of environmental protection requirements for ships by international laws and regulations, introduce the leading international environmental protection technology, coordinate the planning of ship dismantling industry and environmental protection industry, and develop high-tech ship dismantling industry.

2) Developing non-ship products: While promoting the development of ship assembly technology, we should pay attention to the development of the industrial chain of core equipment and accessories on board. Attention should be 
considerable time and effort into their comments on the draft.

Finally, I am indebted to my parents for their continuous support and encouragement.

\section{REFERENCES}

[1] Cao Bo, Tan Songbian, Zhou Rong, et al. Global New Shipbuilding Market Research Report 2017-2018 [R]. Beijing: Economic Research Center of China Shipbuilding Heavy Industry Group Co., Ltd., 2018.

[2] Xu Xiaoli, Zhang Hui, Jin Weichen. 2007-2018 World Marine Engineering Equipment Industry Development Research Report [R]. Beijing: Economic Research Center of China Shipbuilding Heavy Industry Group Co., Ltd., 2018.

[3] Xudi, Sudi, Wu Jialu, et al. Global economic recovery is optimistic for a good shipping market Review of international shipping development in 2017 and outlook for 2018 [N]. China Shipping Daily, 2018-01-21 (1).

[4] Weichen. The development of marine equipment technology has entered a new era [J]. Ship material and market, 2018 (1): 54-55.

[5] Xie Rong, Hu Jie, Xie Yi. Market Development Trend Analysis of Ship and Marine Equipment Manufacturing Industry [J]. Jiangsu Ship, 2018 (12): 35-6.

[6] Dalian Development and Reform Commission. Dalian 13th Five-Year Plan [Z]. 2018-05-14.

This paper mainly discusses the significance of promoting the development of equipment and high-tech ships based on marine engineering, and discusses the future situation of the development of China's marine engineering equipment and high-tech ships in combination with the actual situation, hoping to be helpful for the internationalization of China's marine engineering industry and the long-term stable development.

\section{ACKNOWLEDGMENTS}

First of all, I would like to extend my sincere gratitude to my supervisor, Jian $\mathrm{Na}$, for his instructive advices on my thesis am deeply grateful of her help in the completion of this thesis.

I am also deeply indebted to all the other tutors and teachers in Translation Studies for their direct and indirect help to me. Special thanks should go to my friends who have put 